\title{
UvrD Participation in Nucleotide Excision Repair Is Required for the Recovery of DNA Synthesis following UV-Induced Damage in Escherichia coli
}

\author{
Kelley N. Newton, Charmain T. Courcelle, and Justin Courcelle \\ Department of Biology, Portland State University, Portland, OR 97201, USA \\ Correspondence should be addressed to Kelley N. Newton, knewt@pdx.edu
}

Received 30 April 2012; Accepted 17 July 2012

Academic Editor: Grigory Dianov

Copyright (c) 2012 Kelley N. Newton et al. This is an open access article distributed under the Creative Commons Attribution License, which permits unrestricted use, distribution, and reproduction in any medium, provided the original work is properly cited.

UvrD is a DNA helicase that participates in nucleotide excision repair and several replication-associated processes, including methyl-directed mismatch repair and recombination. UvrD is capable of displacing oligonucleotides from synthetic forked DNA structures in vitro and is essential for viability in the absence of Rep, a helicase associated with processing replication forks. These observations have led others to propose that UvrD may promote fork regression and facilitate resetting of the replication fork following arrest. However, the molecular activity of UvrD at replication forks in vivo has not been directly examined. In this study, we characterized the role UvrD has in processing and restoring replication forks following arrest by UV-induced DNA damage. We show that UvrD is required for DNA synthesis to recover. However, in the absence of UvrD, the displacement and partial degradation of the nascent DNA at the arrested fork occur normally. In addition, damage-induced replication intermediates persist and accumulate in $u v r D$ mutants in a manner that is similar to that observed in other nucleotide excision repair mutants. These data indicate that, following arrest by DNA damage, UvrD is not required to catalyze fork regression in vivo and suggest that the failure of $u v r D$ mutants to restore DNA synthesis following UV-induced arrest relates to its role in nucleotide excision repair.

\section{Introduction}

The accurate duplication of the genome is critical to the survival of any organism. DNA damage, such as that caused by UV irradiation, can disrupt the replication machinery and prevent it from completing its task [1,2]. In Escherichia coli, a number of the cellular events associated with the recovery of replication forks arrested by UV-induced lesions are known to involve several gene products in the RecF pathway [3-5]. Following replication arrest, the nascent lagging stand of DNA is partially degraded through the coordinated activity of the RecJ nuclease and RecQ helicase [4]. The extent of degradation is limited by RecF-O-R, which facilitates loading and formation of a RecA filament at the stalled fork. Both biochemical and cellular studies suggest that RecF, -O, and -R, together with RecA, facilitate strand exchange or regression at the branch point of the arrested fork $[6,7]$. Cellular studies suggest that this processing restores the lesion-containing region to a double-stranded form, allowing nucleotide excision repair to access and repair the lesion $[6,8]$. In the absence of either processing or repair, the recovery is delayed and elevated levels of rearrangements, mutagenesis, and lethality are observed [8-10]. A number of other gene products have also been postulated to participate in aspects of the recovery process but have yet to be examined in vivo.

UvrD is a DNA helicase that participates in both nucleotide excision repair and replication-associated processes. Nucleotide excision repair is the process by which bulky adducts and lesions are removed and repaired from DNA $[11,12]$. During nucleotide excision repair (NER), a heterotetramer, $\mathrm{UvrA}_{2} \mathrm{UvrB}_{2}$, recognizes and binds the damaged region $[11,13,14]$. UvrD acts after incision to release the resulting 10 to $12 \mathrm{bp}$ oligonucleotide and UvrB-UvrC complex from the DNA [15-18]. The resultant gap is then filled in by DNA polymerase I and sealed by DNA ligase [19]. 
During replication, UvrD function is required to displace the nascent DNA strand during methyl-directed mismatch repair, a replication-coupled process that removes mispaired bases [20,21]. It is required for replication of several rollingcircle plasmids [22] and copurifies with DNA polymerase III holoenzyme under some conditions [23]. Conjugational and transformational recombination frequencies increase in uvrD mutants $[24,25]$ and decrease in strains overexpressing UvrD [26]. In addition, $u v r D$ mutants are constitutively induced for the SOS response and show elevated levels of RecA foci $[27,28]$.

The concept that UvrD may process replication forks following arrest comes from a number of genetic observations. uvrD mutants exhibit synthetic lethality with rep $[29,30]$, which encodes another $3^{\prime}-5^{\prime}$ helicase that is required for the replication of phage $\Phi$ X174 and some plasmids $[31,32]$ and is postulated to remove obstacles on the DNA during replication such as bound proteins or transcriptional machinery [33,34]. Viability in uvrD rep double mutants can be restored by mutations in $r e c F$, recO, and $r e c R$, which are required to process and restore replication following arrest by DNA damage $[5,6,35]$. Subsequent studies found that purified UvrD was capable of displacing oligos and RecA filaments from synthetic replication fork structures in vitro $[36,37]$. These observations led some researchers to speculate that, in addition to its other roles, UvrD function may participate in displacement of the lagging strand and RecA filament from arrested replication forks [37, 38]. However, the molecular function of UvrD at replication forks has not been directly examined in vivo.

Here we characterize the role of $\mathrm{UvrD}$ at the replication fork following arrest by UV-induced damage in vivo. We find that UvrD is necessary for DNA synthesis to resume following UV irradiation. However, the initial degradation, processing and regression of the arrested fork occur normally in the absence of UvrD. Similar to other mutants deficient in nucleotide excision repair, the regressed fork structures fail to resolve in $u v r D$ mutants and continue to accumulate and persist. These observations indicate that $\mathrm{UvrD}$ is not required to catalyze fork regression in vivo and support the idea that the hypersensitivity and failure to restore replication in the absence of UvrD are likely due to its role in nucleotide excision repair.

\section{Materials and Methods}

2.1. Bacterial Strains. All bacterial strains used in this study are in an SR108 background, a thyA36 deoC2 derivative of W3110 [39]. SR108, CL579 (SR108 recF332::Tn3), HL952 (SR108 uvrA::Tn10), HL1054 (HL108 uvrD::tetR), and HL944 (SR108 recQ1803::Tn3) have been described previously $[4,6,8,40]$. CL1272 (DY320 uvrD::kan) was constructed using the recombineering strain DY329 [41]. The kanamycin resistance gene was amplified from Tn5 using PCR primers 5'CCCAACCTATTTTTACGCGGCGGTGCCAATGGACGTTTCT-ATGGACAGCAAGCGAACCG3' and 5'AGGCCAAATAAGGTGCGCAGCACCGCATC-CGGCAACGTTATCAGAACTCGTCAAGAAG3'. The
PCR product was then transformed into DY329 to generate CL1272, selecting for kanamycin resistance. The gene replacement was transferred into SR108 using standard P1 transduction to generate CL1302 (SR108 uvrD::kan).

2.2. UV Survival Studies. Fresh overnight cultures were diluted $1: 100$ in DGCthy medium (Davis medium supplemented with $0.4 \%$ glucose, $0.2 \%$ casamino acids, and $10 \mu \mathrm{g} / \mathrm{mL}$ thymine) and grown to an $\mathrm{OD}_{600}$ of between 0.4 and 0.5 at $37^{\circ} \mathrm{C}$ in a shaking bath. Serial dilutions of each culture were plated in triplicate on Luria-Bertania plates supplemented with $10 \mu \mathrm{g} / \mathrm{mL}$ thymine and UV irradiated with the indicated doses. A Sylvania 15 watt germicidal lamp $(254 \mathrm{~nm})$ delivering an incident dose of $0.9 \mathrm{~J} / \mathrm{m}^{2} / \mathrm{s}\left(0.2 \mathrm{~J} / \mathrm{m}^{2} / \mathrm{s}\right.$ for doses less than $20 \mathrm{~J} / \mathrm{m}^{2}$ ) was used for all irradiations. Plates were grown overnight at $37^{\circ} \mathrm{C}$, and colonies were counted the following day.

2.3. Recovery of DNA Synthesis. Fresh overnight cultures were diluted $1: 100$ in $50 \mathrm{~mL}$ DGCthy medium supplemented with $0.1 \mu \mathrm{Ci} / \mathrm{mL}\left[{ }^{14} \mathrm{C}\right]$-thymine and grown to an $\mathrm{OD}_{600}$ of 0.3 at $37^{\circ} \mathrm{C}$ in a shaking water bath. Half of each culture was mock-irradiated, and the other half was irradiated with an incident dose of $27 \mathrm{~J} / \mathrm{m}^{2}$. At the indicated times, duplicate $0.5 \mathrm{~mL}$ aliquots of each culture were pulse-labeled with $1 \mu \mathrm{Ci} / \mathrm{mL}\left[{ }^{3} \mathrm{H}\right]$-thymidine for $2 \mathrm{~min}$ at $37^{\circ} \mathrm{C}$. The cells were then lysed and the DNA precipitated using ice-cold $5 \%$ trichloroacetic acid (TCA). The DNA was filtered onto $2.4 \mathrm{~cm}$ Fisherbrand glass fiber filters, and the amount of ${ }^{14} \mathrm{C}$ and ${ }^{3} \mathrm{H}$ was determined using a liquid scintillation counter.

2.4. DNA Degradation Assay. Fresh overnight cultures were diluted $1: 100$ in $6 \mathrm{~mL}$ DGCthy medium supplemented with $0.1 \mu \mathrm{Ci} / \mathrm{mL}\left[{ }^{14} \mathrm{C}\right]$-thymine and grown to an $\mathrm{OD}_{600}$ of 0.3 in a shaking water bath at $37^{\circ} \mathrm{C}$. At this point, cultures were pulse-labeled for $5 \mathrm{~s}$ with $1 \mu \mathrm{Ci} / \mathrm{mL}\left[{ }^{3} \mathrm{H}\right]$-thymidine, filtered onto a 0.45 micron Millapore filter, and rinsed twice with $1 \mathrm{X}$ NET buffer (100 mM NaCl, 10 mM EDTA, pH 8.0, $10 \mathrm{mM}$ Tris, $\mathrm{pH}$ 8.0). The cells were then resuspended in $10 \mathrm{~mL}$ nonradioactive, prewarmed DGCthy media, UV-irradiated at an incident dose of $27 \mathrm{~J} / \mathrm{m}^{2}$, and incubated in a $37^{\circ} \mathrm{C}$ shaking water bath. Triplicate $0.2 \mathrm{~mL}$ samples were taken at time zero, followed by duplicate samples every $20 \mathrm{~min}$ for the duration of the experiment. These samples were added to $5 \%$ TCA to lyse the cells and precipitate the DNA. The DNA was filtered onto $2.4 \mathrm{~cm}$ Fisherbrand glass fiber filters, and the amount of radioactivity on each filter was measured using a liquid scintillation counter.

2.5. Two-Dimensional Agarose Gel Electrophoresis. Cultures harboring the pBR322 plasmid were grown overnight in DGCthy medium in the presence of $100 \mu \mathrm{g} / \mathrm{mL}$ ampicillin. One milliliter of this culture was pelleted, resuspended at a 1:100 ratio in $20 \mathrm{~mL}$ of DGCthy medium, and grown without ampicillin to an $\mathrm{OD}_{600}$ of 0.5 at $37^{\circ} \mathrm{C}$ in a shaking water bath. The cultures were then UV-irradiated with $50 \mathrm{~J} / \mathrm{m}^{2}$, and $0.75 \mathrm{~mL}$ aliquots were transferred to an equal volume of ice-cold 2X NET ( $200 \mathrm{mM} \mathrm{NaCl}, 20 \mathrm{mM}$ EDTA 
$\mathrm{pH}$ 8.0, $20 \mathrm{mM}$ Tris, $\mathrm{pH} 8.0$ ) at the times indicated. These samples were then pelleted, resuspended in $0.14 \mathrm{~mL}$ of lysis buffer $(1.5 \mathrm{mg} / \mathrm{mL}$ lysozyme, $0.5 \mathrm{mg} / \mathrm{mL}$ RNase A in $10 \mathrm{mM}$ Tris, $\mathrm{pH}$ 8.0, $1 \mathrm{mM}$ EDTA, $\mathrm{pH} 8.0$ ), and incubated at $37^{\circ} \mathrm{C}$. After $30 \mathrm{~min}, 10 \mu \mathrm{L}$ of $20 \%$ Sarkosyl and $10 \mu \mathrm{L}$ of $10 \mathrm{mg} / \mathrm{mL}$ proteinase $\mathrm{K}$ were added and the incubation was continued for 30 more min. The samples were then extracted twice with 4 volumes of phenol/chloroform/isoamyl alcohol $(25: 24: 1)$ and extracted once with 4 volumes of chloroform/isoamyl alcohol $(24: 1)$. The samples were dialyzed against $200 \mathrm{~mL}$ of TE buffer (2 mM Tris, pH 8.0, 1 mM EDTA, pH 8.0) for $1 \mathrm{~h}$ on floating $37 \mathrm{~mm}$ Whatman $0.05 \mu \mathrm{m}$ pore discs and digested with PvuII overnight at $37^{\circ} \mathrm{C}$. The samples were loaded onto $0.4 \%$ agarose gel following extraction with 2 volumes of chloroform/isoamyl alcohol $(24: 1)$ and run at $25 \mathrm{~V}$ for 16 hours in 1X TBE buffer (Tris-borate-EDTA, pH 8.0). For the second dimension, the lanes were excised, rotated 90 degrees, recast in a $1 \%$ agarose gel in $1 \mathrm{X} \mathrm{TBE}$, and the gel was electrophoresed at $200 \mathrm{~V}$ for $7 \mathrm{~h}$. The DNA from the gels was transferred to a HybondN+ nylon membrane by standard Southern blotting, and the plasmid DNA was detected with an $\left[\alpha-{ }^{32} \mathrm{P}\right] \mathrm{dCTP}$ (MP Biomedicals) labeled pBR322 probe that was prepared using a nick translation protocol (Roche). Radioactivity was visualized and quantified using a Storm 840 Phosphoimager and ImageQuant software (GE LifeSciences).

\section{Results}

3.1. UvrD Is Required to Restore DNA Synthesis following Arrest by UV Damage. We constructed a UvrD deletion, uvrD::kan and compared its UV resistance along with a previously characterized strain, uvrD::tet (parental strain HL 1054 [40]), with that of $u v r A$ and recF mutants (Figure 1). UvrA is required for the initial step of nucleotide excision repair and $\mathrm{RecF}$ is required for processing and maintaining forks arrested by UV-induced damage. Both uvrD mutations rendered cells more sensitive to UV irradiation than wildtype cells. Consistent with previous studies, uvrD mutants are more sensitive than $r e c F$ mutants [42] but less sensitive than $u v r A$ mutants [43]. The higher resistance of $u v r D$ compared with uvrA can be explained by its role in turnover of UvrC. uvrD mutants retain a limited ability to carry out nucleotide excision repair, and remain proficient in repairing 6-4 photoproducts, which are removed preferentially before cyclobutane pyrimidine dimers or lesions in transcribed genes [40]. It is also important to note that $r e c F$ mutants are able to withstand considerably more UV exposure than $u v r D$ mutants. The RecF protein is involved in the stabilization of disrupted replication forks, and, consequently, the susceptibility of recF mutants to UV damage is related to the frequency with which the replication machinery encounters a lesion. In the presence of nucleotide excision repair, the frequency of these events is substantially decreased. Therefore, that the $u v r D$ mutant is considerably more sensitive than the recF mutant would indicate that the UvrD protein still plays a substantial role in nucleotide excision repair.

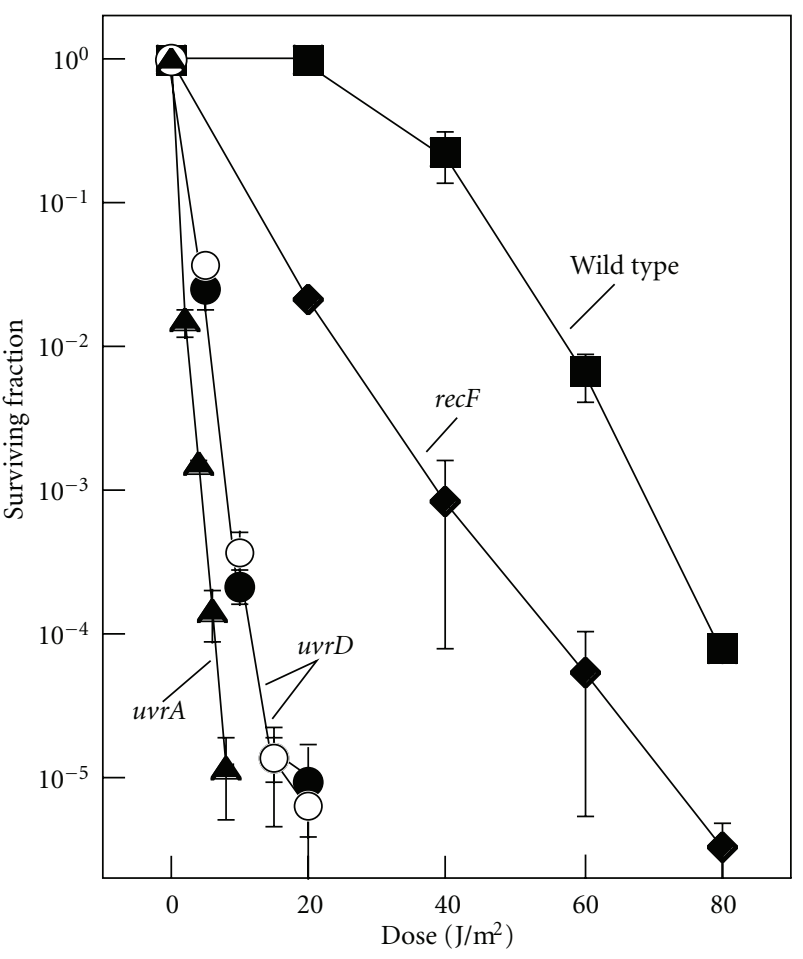

FIGURE 1: Cells lacking UvrD are hypersensitive to irradiation with

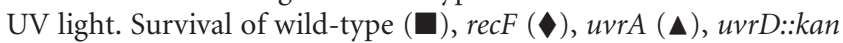
(O), and uvrD::tet $(\bigcirc)$ cultures following irradiation with the indicated UV doses. Error bars represent the standard error of the mean.

To determine if UvrD is required to resume DNA replication following arrest by UV-induced damage, we monitored DNA synthesis over time in UV-irradiated cultures of $u v r D$ mutants. Cultures grown in the presence of ${ }^{14} \mathrm{C}$-thymine were UV-irradiated or mock-irradiated and allowed to recover over a period of $90 \mathrm{~min}$. The rate of synthesis was monitored by pulse-labeling aliquots of the culture with ${ }^{3} \mathrm{H}$-thymidine for two min at various times during the recovery period. In this manner, both the total DNA accumulation $\left({ }^{14} \mathrm{C}\right.$-incorporation) and the rate of synthesis $\left({ }^{3} \mathrm{H}\right.$-incorporation $\left./ 2 \mathrm{~min}\right)$ can be followed simultaneously. By this assay in wild-type cells, the rate of synthesis dropped over $90 \%$ immediately following UV-irradiation and then began to recover after approximately $20 \mathrm{~min}$ and approached preirradiation levels by the end of the $90 \mathrm{~min}$ time course. A transient pause in the accumulation of DNA in the wildtype culture was also observed consistently at times prior to when replication resumed (Figure 2). For the purposes of comparison, we also examined mutants lacking RecF and UvrA, which have been shown previously to be defective in the resumption of replication following arrest by UV damage [5]. In these mutants, no further DNA accumulation was observed following irradiation and the rate of synthesis did not recover (Figure 2). When we examined UV-irradiated cultures of $u v r D$, we observed that the rate of DNA synthesis was inhibited to a similar extent as in recF and $u v r A$ cultures after irradiation and also failed to recover (Figure 2). Additionally, no further accumulation of DNA was observed 

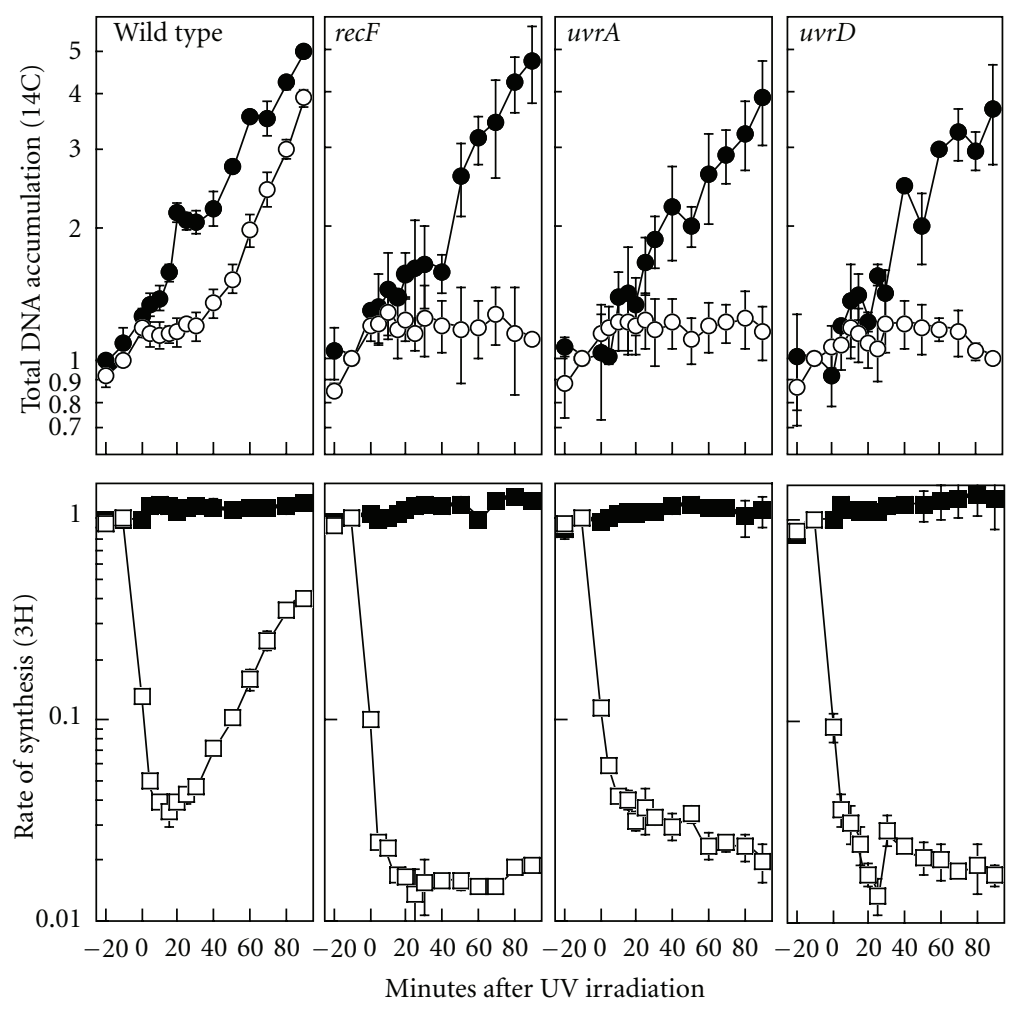

FIGURE 2: UvrD is required for the recovery of replication following UV irradiation, but not for replication in the absence of damage. Cells grown in the presence of $\left[{ }^{14} \mathrm{C}\right]$-thymine were pulse-labeled for $2 \mathrm{~min}$ with $\left[{ }^{3} \mathrm{H}\right]$-thymidine at the times indicated following either UV irradiation with $27 \mathrm{~J} / \mathrm{m}^{2}$ (open symbols) or mock irradiation (closed symbols). Total DNA accumulation $\left({ }^{14} \mathrm{C}\right.$ incorporation, circles) and rate of synthesis $\left({ }^{3} \mathrm{H}\right.$ incorporation/ $2 \mathrm{~min}$, squares) are plotted. Graphs represent the average of at least three independent experiments. Error bars represent the standard error of the mean. The level of $\left[{ }^{3} \mathrm{H}\right]$ and $\left[{ }^{14} \mathrm{C}\right]$ in preirradiated DNA ranged between $30,000-50,000 \mathrm{cpm}$ and 3000-6000 cpm for all experiments.

in these cultures. The results indicate that UvrD is necessary for the resumption of replication following arrest by UVinduced damage.

3.2. UvrD Does Not Contribute to the Nascent DNA Processing That Occurs following Arrest at UV-Induced Damage. Following the arrest of replication by UV-induced damage, the nascent DNA at the replication fork is displaced and partially degraded prior to the resumption of replication [4]. Recent studies have postulated that UvrD may function in clearing and processing of blocked replication forks, which may account for its failure to restore DNA synthesis [38, 44, 45]. Alternatively, UvrD may function at forks blocked by UV damage specifically in a nucleotide excision repair capacity. To determine which roles of UvrD may be required in replication recovery following UV damage, we examined whether UvrD contributes to the displacement and degradation of the nascent DNA at replication forks arrested by UV-induced damage. We reasoned that if the UvrD helicase were required to displace the nascent DNA, then the degradation of the nascent DNA at the arrested replication fork would be reduced in the protein's absence. To monitor DNA degradation, cultures grown in media containing ${ }^{14} \mathrm{C}$-thymine were pulse-labeled for $5 \mathrm{~s}$ with ${ }^{3} \mathrm{H}$-thymidine, collected on filters, resuspended in nonradioactive media, and immediately UV-irradiated. The amount of radioactivity remaining in the cultures was then followed over time. The dual radio-labeling allows us to simultaneously monitor the degradation that occurs in the total genomic DNA $\left({ }^{14} \mathrm{C}\right)$ and the nascent DNA synthesized immediately prior to irradiation $\left({ }^{3} \mathrm{H}\right)$. Following irradiation of wild-type cultures, the genomic DNA primarily remained intact and little or no degradation was detected (Figure 3). However, consistent with earlier studies, some limited degradation of the nascent DNA was detected at early times following irradiation $[4,8]$. The loss of ${ }^{3} \mathrm{H}$-labeled DNA ceased at a time that correlated with the resumption of DNA synthesis and then began to increase (Figure 3 ). In principle, an increase in ${ }^{3} \mathrm{H}$ should not be possible with this assay design. Previous work has shown that this increase is most likely due to remaining intracellular pools of radio-labeled thymidine that could not be washed away [5]. In the absence of RecF, which is required to limit the degradation at blocked replication forks, the nascent DNA degradation was more extensive and continued over a longer duration until approximately $50 \%$ of the nascent DNA has been degraded (Figure 3). In previous work, we have shown that the lagging strand is preferentially degraded following UV irradiation. This may explain why the degradation ceases after half of the nascent DNA has been degraded [4]. For the purposes of comparison, we also examined the degradation 

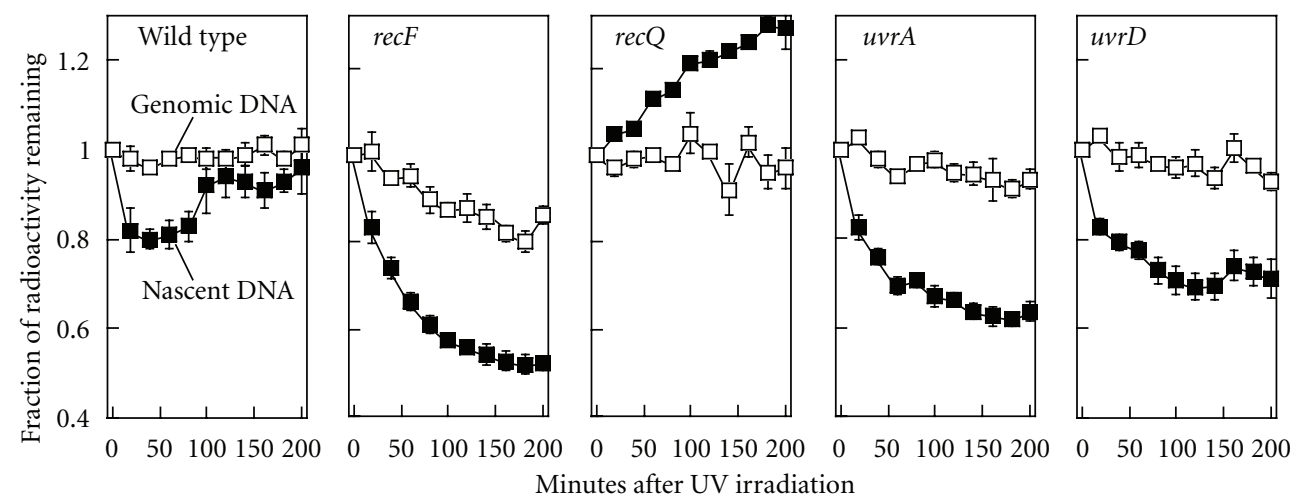

Figure 3: In the absence of UvrD, the nascent DNA at stalled replication forks is degraded in a manner similar to other repair mutants. $\left[{ }^{14} \mathrm{C}\right]$-thymine-labeled cultures were pulse-labeled with $\left[{ }^{3} \mathrm{H}\right]$-thymidine for $5 \mathrm{~s}$ before the cells were collected, resuspended in nonradioactive media, and UV-irradiated with $27 \mathrm{~J} / \mathrm{m}^{2}$. The fraction of ${ }^{14} \mathrm{C}$-labeled genomic DNA $(\square)$ and ${ }^{3} \mathrm{H}$-labeled nascent DNA ( $\square$ ) remaining over time is plotted. Graphs represent the average of three independent experiments. The level of $\left[{ }^{3} \mathrm{H}\right]$ and $\left[{ }^{14} \mathrm{C}\right]$ in DNA immediately preceding irradiation ranged between $2500-7000 \mathrm{cpm}$ and $1000-2500 \mathrm{cpm}$ in all experiments. Error bars represent the standard error of the mean.

occurring in recQ and $u v r A$ mutants. RecQ is a helicase that has been demonstrated to participate with RecJ to displace and degrade the nascent DNA at replication forks blocked by UV-induced damage [4]. In recQ mutants, no degradation of the nascent DNA was observed following irradiation and the remaining intracellular pools of ${ }^{3} \mathrm{H}$-labelled thymidine were rapidly incorporated (Figure 3). UvrA is required for the initial recognition step of nucleotide excision repair and is not thought to play any role in processing of the replication fork. Following irradiation of uvrA mutants, we observed that the nascent DNA degradation still occurred, consistent with what has been reported previously (Figure 3 and [4, $8]$ ). When we examined UV-irradiated cultures of $u v r D$, we observed that degradation of the nascent DNA occurred and was similar in extent to that seen in $u v r A$ mutants (Figure 3 ). The data indicate that when replication is arrested by UVinduced damage, UvrD is not required for and does not contribute to the degradation of the nascent DNA in vivo.

\subsection{UV-Induced Replication Intermediates Accumulate and} Persist in uvrD Mutants. To further differentiate between a potential role for $\mathrm{UvrD}$ in nucleotide excision repair and in processing replication forks, we compared the structural intermediates that are formed at replication forks following UV irradiation in $u v r D$ mutants to $u v r A$ and recF mutants. Previous work has shown that defects in nucleotide excision repair or replication fork regression lead to different structural intermediates following arrest [6]. Intermediates were visualized on replicating molecules of the pBR322 plasmid using a two-dimensional (2D) gel electrophoresis technique. Replicating cells containing this plasmid were irradiated with $50 \mathrm{~J} / \mathrm{m}^{2}$, a dose that produces approximately one lesion per plasmid strand [6]. Cells were harvested at various times after irradiation, and the DNA was purified and digested with PvuII, which linearizes the plasmid proximal to its unidirectional origin of replication. The replication intermediates were then examined using 2D agarose-gel electrophoresis and Southern analysis with
${ }^{32} \mathrm{P}$-labeled pBR322 as a probe. In the absence of damage, nonreplicating plasmids migrate as a linear $4.5 \mathrm{~kb}$ fragment, which forms the prominent large spot on the blot (Figure 4(a)). Replicating molecules, which form Y-shapes, migrate more slowly due to their increased size and nonlinear shape and appear as an arc extending out from the spot of linear plasmid fragments. Following irradiation of wild-type cultures, a transient cone region is observed above the arc of replicating Y-shaped molecules, consisting of X-shaped and double Y-shaped molecules (Figure 4). In previous work, we demonstrated that a portion of these molecules represent products that were formed by a RecF-catalyzed regression of the replication fork DNA $[3,6,46]$. These damage-induced intermediates begin to resolve after $30 \mathrm{~min}$, at a time that correlates with the removal of lesions and the recovery of replication. In the absence of RecF, the arrested fork DNA is not maintained and these intermediate structures are not observed (Figure 4). By contrast, in uvrA mutants, the fork regression occurs normally but fails to resolve as the obstructing lesion is not removed from the DNA. In these mutants, the regressed fork intermediate is seen to persist and accumulate, forming higher-order, illegitimate intermediates by the end of the $90 \mathrm{~min}$ time course (Figures 4(b) and $4(\mathrm{c}))$.

We reasoned that if UvrD was required to catalyze the regression of the fork DNA at UV-induced lesions, then the cone region intermediates would be reduced or absent in these mutants following UV irradiation. However, when we examined $u v r D$ mutants, we observed elevated levels of these intermediates that accumulated throughout the 90 min time course (Figure 4). These intermediates went on to form the higher-order intermediates that are a hallmark of nucleotide excision repair-deficient mutants, consistent with the high levels of recombination and strand exchange seen in these mutants $[9,10]$.The presence of the fork regression products in $u v r D$ mutants indicates that $\mathrm{UvrD}$ is not required to catalyze this reaction in vivo. Further, the similarity between the intermediates seen in $u v r A$ and $u v r D$ mutants would suggest that the failure of $u v r D$ mutants to resume DNA 


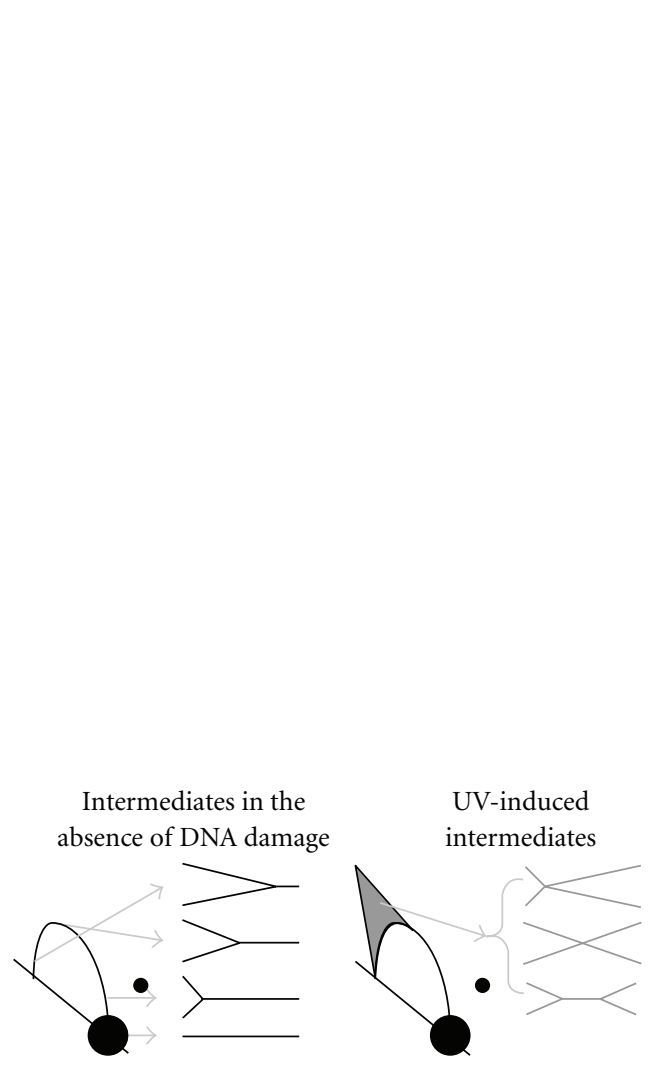

(a)

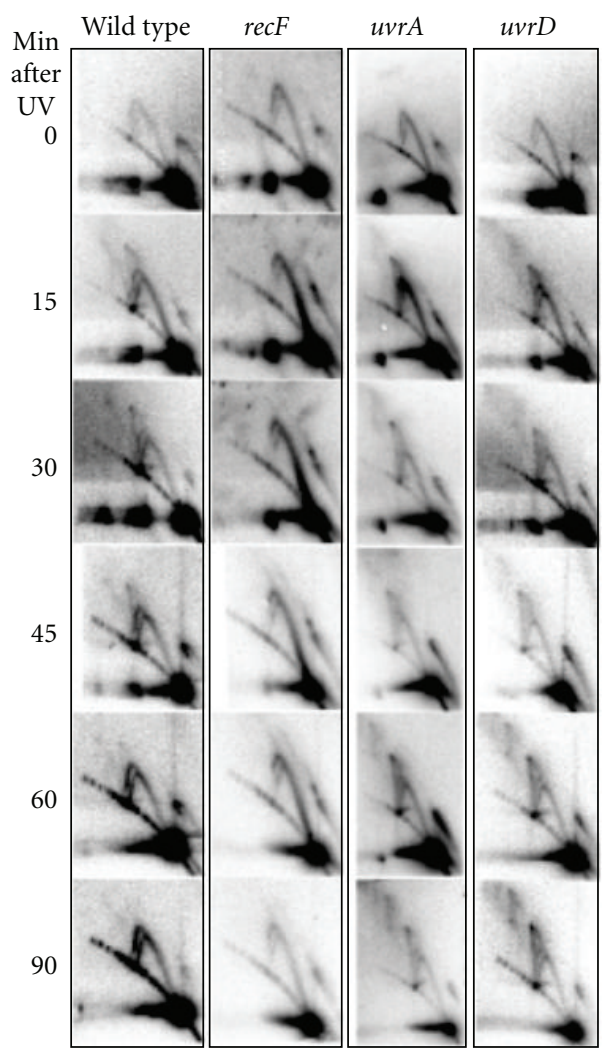

(b)

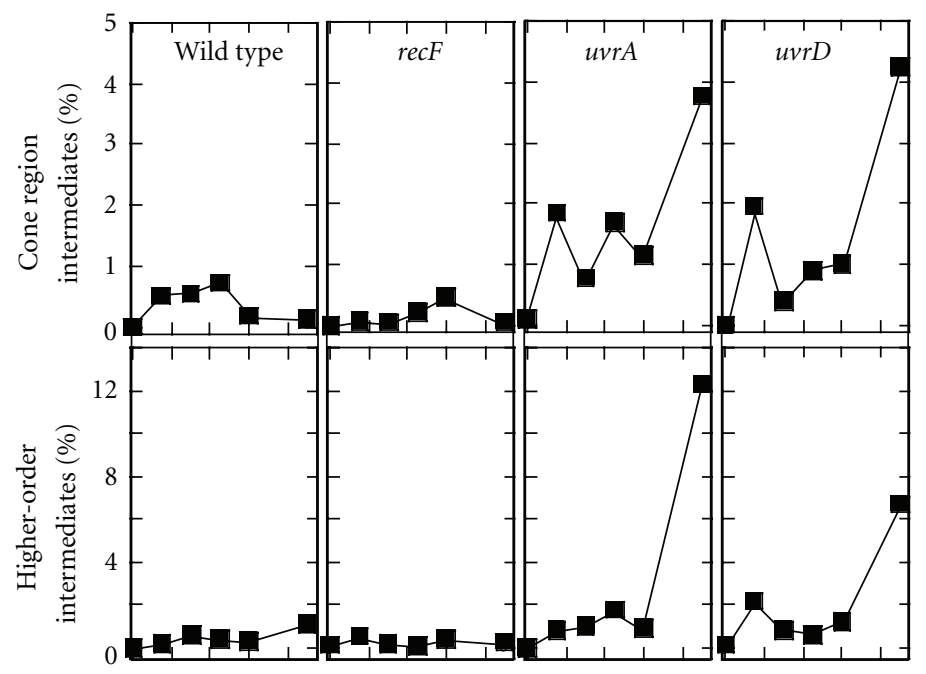

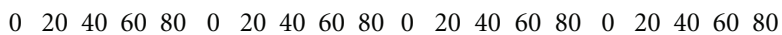
Minutes after UV

(c)

FIGURE 4: In the absence of UvrD, blocked replication forks persist leading to the accumulation of higher-order recombination intermediates in a manner similar to uvrA mutants. (a) Diagram of structural intermediates observed in the presence or absence of UV-induced damage. (b) Cells containing the pBR322 plasmid were UV-irradiated with $50 \mathrm{~J} / \mathrm{m}^{2}$. At the times indicated, genomic DNA was purified, digested with PvuII, and the structural intermediates were examined by two-dimensional agarose gel analysis. Gels shown are representative of at least two independent experiments. (c) The percentage of UV-induced intermediates relative to nonreplicating plasmids over time is plotted. Percentages were quantified as the ratio of radioactivity in either the cone region or the high-order intermediate region over the amount of radioactivity in the nonreplicating region. 
synthesis after UV irradiation is most likely due to their inability to carry out nucleotide excision repair.

\section{Discussion}

In addition to its role in nucleotide excision repair, $\mathrm{UvrD}$ has also been postulated to catalyze fork regression and the displacement of the nascent lagging strand during the recovery of replication after arrest $[36,44,45]$. Here, we examined the functional roles for UvrD's contribution to cell survival and the recovery of replication following arrest by UV-induced damage. We observed that both the nascent strand processing and regression of the fork DNA occurs normally in the absence of UvrD. Rather than diminished levels of regressed fork intermediates forming in $u v r D$ mutants, we observed that elevated levels of these intermediates formed and accumulated, similar to that seen in other nucleotide excision repair mutants. The observations are most consistent with the idea that the failure to restore replication in UvrD mutants is due to its role in nucleotide excision repair.

A role of $\mathrm{UvrD}$ in nucleotide excision repair, by itself, could sufficiently account for the hypersensitive and replication-defective phenotypes observed in $u v r D$ mutants after UV irradiation. UvrD is required for the turnover of UvrC, which is not upregulated during the SOS response [47]. Thus, only a limited amount of repair occurs in the absence of UvrD, which is generally restricted to the repair of 6,4-photoproducts [40]. The minimal amount of nucleotide excision repair seen in $u v r D$ mutants is consistent with it being modestly more resistant to UV damage than other repair mutants of this class. Otherwise, with respect to the processing of the nascent DNA, fork reversal, and impaired recovery of replication, $u v r D$ mutants exhibit phenotypes nearly identical to those of other nucleotide excision repair mutants.

The concept that UvrD may function in displacing the nascent DNA and promote fork reversal following arrest developed from a number of indirect genetic observations. A series of previous studies observed that in $\operatorname{rec} B C$ mutants, which are defective in double-strand break repair, elevated levels of chromosome breaks can be detected in thermosensitive replication mutants, $d n a E$ and $d n a N$ (the catalytic subunit of Pol III and the Pol III clamp, resp. $[48,49])$ at the restrictive temperature $[37,44,45]$. If cells were additionally mutated in $u v r D$, the level of detectable chromosome breaks was reduced. The authors speculated that these chromosome breaks arose as a result of replication forks collapsing to generate double-strand breaks. However, the assays employed in these studies were unable to address where the breaks form in the chromosome, and other studies have suggested that breaks repaired by RecBC do not form directly at the replication forks following arrest in vivo $[4,5$, 50]. Curiously, these studies also noted that a different $u v r D$ mutant lacking both ATPase and helicase activity failed to suppress chromosome breaks in these backgrounds.

When considering the differences between the results obtained in these studies, it is also important to consider the mechanism by which replication is arrested in each case. Whereas we used UV-induced damage to block the replication machinery, studies observing chromosomal breaks have often disrupted the replisome proteins themselves, using thermosensitive mutants. It seems probable that the biological events occurring after the loss of replication proteins would be distinct from those that occur when replication is blocked by impediments such as proteins or lesions, especially if one assumes that the replication proteins are required for the natural recovery process. Consistent with this, previous work from our lab has demonstrated a marked difference between the events following replication arrest caused by UV-induced damage and disruption of the DnaB helicase [51]. Whereas replication forks blocked by UV-induced lesions are protected and maintained by the RecFOR proteins, disruption or loss of DnaB helicase results in the collapse and degradation of the replication fork, a process that is antagonized by RecFOR function [51].

Other genetic studies have inferred a role for UvrD in processing replication forks based on the synthetic lethality between rep and $u v r D$ mutants $[29,35]$. The Rep helicase is suggested to play a role in removing nucleoproteins, DNA secondary structures, or transcriptional machinery encountered by the replisome during replication [34, 52]. These observations have been interpreted to suggest that UvrD may be partially redundant with Rep function in removing nucleoprotein impediments encountered during replication [34]. However, both Rep and UvrD are directly associated with replication processes and it is unclear whether the synthetic lethality of rep uvrD double mutants can be attributed to the inability to overcome transcriptional blocks to replication or as a result of other impediments.

We have shown that when replication is blocked by UVinduced damage, it does not contribute to the displacement of the lagging strand or replication fork reversal but is required to carry out nucleotide excision repair before replication can resume. We do not rule out the possibility that $\mathrm{UvrD}$ contributes to fork processing when replication encounters other impediments, such as DNA-bound proteins, RNA polymerases, or even other forms of damage. It would be of interest to pursue these investigations in future studies as well as address how UvrD can generate chromosome breaks in the unusual case where replication proteins are targeted for disruption using thermosensitive mutants.

\section{Acknowledgment}

This work was funded by an AREA Grant from the National Institutes of Health/National Institute of Environmental Health Sciences (R15 ES021594-01).

\section{References}

[1] G. L. Chan, P. W. Doetsch, and W. A. Haseltine, "Cyclobutane pyrimidine dimers and (6-4) photoproducts Block polymerization by DNA polymerase I," Biochemistry, vol. 24, no. 21, pp. 5723-5728, 1985.

[2] J. A. Lippke, L. K. Gordon, D. E. Brash, and W. A. Haseltine, "Distribution of UV light-induced damage in 
a defined sequence of human DNA: detection of alkalinesensitive lesions at pyrimidine nucleoside-cytidine sequences," Proceedings of the National Academy of Sciences of the United States of America, vol. 78, no. 6, pp. 3388-3392, 1981.

[3] K. H. Chow and J. Courcelle, "RecO acts with RecF and RecR to protect and maintain replication forks blocked by UVinduced DNA damage in Escherichia coli," Journal of Biological Chemistry, vol. 279, no. 5, pp. 3492-3496, 2004.

[4] J. Courcelle and P. C. Hanawalt, "RecQ and RecJ process blocked replication forks prior to the resumption of replication in UV-irradiated Escherichia coli," Molecular and General Genetics, vol. 262, no. 3, pp. 543-551, 1999.

[5] J. Courcelle, C. Carswell-Crumpton, and P. C. Hanawalt, "recF and recR are required for the resumption of replication at DNA replication forks in Escherichia coli," Proceedings of the National Academy of Sciences of the United States of America, vol. 94, no. 8, pp. 3714-3719, 1997.

[6] J. Courcelle, J. R. Donaldson, K. H. Chow, and C. T. Courcelle, "DNA damage-induced replication fork regression and processing in Escherichia coli," Science, vol. 299, no. 5609, pp. 1064-1067, 2003.

[7] B. L. Webb, M. M. Cox, and R. B. Inman, "Recombinational DNA repair: the RecF and RecR proteins limit the extension of RecA filaments beyond single-strand DNA gaps," Cell, vol. 91, no. 3, pp. 347-356, 1997.

[8] J. Courcelle, D. J. Crowley, and P. C. Hanawalt, "Recovery of DNA replication in UV-irradiated Escherichia coli requires both excision repair and RecF protein function," Journal of Bacteriology, vol. 181, no. 3, pp. 916-922, 1999.

[9] W. D. Rupp, C. E. Wilde, D. L. Reno, and P. Howard-Flanders, "Exchanges between DNA strands in ultraviolet-irradiated Escherichia coli," Journal of Molecular Biology, vol. 61, no. 1, pp. 25-44, 1971.

[10] W. D. Rupp and P. Howard-flanders, "Discontinuities in the DNA synthesized in an Excision-defective strain of Escherichia coli following ultraviolet irradiation," Journal of Molecular Biology, vol. 31, no. 2, pp. 291-304, 1968.

[11] L. Grossman and S. Thiagalingam, "Nucleotide excision repair, a tracking mechanism in search of damage," Journal of Biological Chemistry, vol. 268, no. 23, pp. 16871-16874, 1993.

[12] A. Sancar, "DNA excision repair," Annual Review of Biochemistry, vol. 65, pp. 43-81, 1996.

[13] E. Malta, G. F. Moolenaar, and N. Goosen, "Dynamics of the UvrABC nucleotide excision repair proteins analyzed by fluorescence resonance energy transfer," Biochemistry, vol. 46, no. 31, pp. 9080-9088, 2007.

[14] N. M. Kad, H. Wang, G. G. Kennedy, D. M. Warshaw, and B. Van Houten, "Collaborative dynamic DNA scanning by nucleotide excision repair proteins investigated by singlemolecule imaging of quantum-dot-labeled proteins," Molecular Cell, vol. 37, no. 5, pp. 702-713, 2010.

[15] W. D. Rupp, A. Sancar, and G. B. Sancar, "Properties and regulation of the UVRABC endonuclease," Biochimie, vol. 64, no. 8-9, pp. 595-598, 1982.

[16] J. J. Lin and A. Sancar, "Reconstitution of nucleotide excision nuclease with UvrA and UvrB proteins from Escherichia coli and UvrC protein from Bacillus subtilis," Journal of Biological Chemistry, vol. 265, no. 34, pp. 21337-21341, 1990.

[17] N. Goosen and G. F. Moolenaar, "Repair of UV damage in bacteria," DNA Repair, vol. 7, no. 3, pp. 353-379, 2008.

[18] S. W. Matson, "Escherichia coli helicase II (urvD gene product) translocates unidirectionally in a $3^{\prime}$ to $5^{\prime}$ direction," Journal of Biological Chemistry, vol. 261, no. 22, pp. 10169-10175, 1986.
[19] Sibghat-Ullah, A. Sancar, and J. E. Hearst, "The repair patch of E. coli (A)BC excinuclease," Nucleic Acids Research, vol. 18, no. 17, pp. 5051-5053, 1990.

[20] A. L. Lu, S. Clark, and P. Modrich, "Methyl-directed repair of DNA base-pair mismatches in vitro," Proceedings of the National Academy of Sciences of the United States of America, vol. 80, no. 15, pp. 4639-4643, 1983.

[21] M. Yamaguchi, V. Dao, and P. Modrich, "MutS and MutL activate DNA helicase II in a mismatch-dependent manner," Journal of Biological Chemistry, vol. 273, no. 15, pp. 91979201, 1998.

[22] C. Bruand and S. D. Ehrlich, "UvrD-dependent replication of rolling-circle plasmids in Escherichia coli," Molecular Microbiology, vol. 35, no. 1, pp. 204-210, 2000.

[23] R. S. Lahue and P. Modrich, "DNA mismatch correction in a defined system,” Science, vol. 245, no. 4914, pp. 160-164, 1989.

[24] J. Zieg, V. F. Maples, and S. R. Kushner, "Recombination levels of Escherichia coli K-12 mutants deficient in various replication, recombination, or repair genes," Journal of Bacteriology, vol. 134, no. 3, pp. 958-966, 1978.

[25] H. M. Arthur and R. G. Lloyd, "Hyper-recombination in uvrD mutants of Escherichia coli K-12," Molecular and General Genetics, vol. 180, no. 1, pp. 185-191, 1980.

[26] V. P. Maples and S. R. Kushner, "DNA repair in Escherichia coli: Identification of the uvrD gene product," Proceedings of the National Academy of Sciences of the United States of America, vol. 79, no. 18 I, pp. 5616-5620, 1982.

[27] R. C. Centore and S. J. Sandler, "UvrD limits the number and intensities of recA-green fluorescent protein structures in Escherichia coli K-12," Journal of Bacteriology, vol. 189, no. 7, pp. 2915-2920, 2007.

[28] N. Ossanna and D. W. Mount, "Mutations in uvrD induce the SOS response in Escherichia coli," Journal of Bacteriology, vol. 171, no. 1, pp. 303-307, 1989.

[29] G. Taucher-Scholz, M. Abdel-Monem, and H. HoffmannBerling, "Functions of DNA Helicases in Escherichia coli," in Mechanisms of DNA Replication and Recombination, pp. 6576, 1983.

[30] H. E. D. Lane and D. T. Denhardt, "The rep mutation. IV. Slower movement of replication forks in Escherichia coli rep strains," Journal of Molecular Biology, vol. 97, no. 1, pp. 99112, 1975.

[31] G. T. Yarranton and M. L. Gefter, "Enzyme-catalyzed DNA unwinding: studies on Escherichia coli rep protein," Proceedings of the National Academy of Sciences of the United States of America, vol. 76, no. 4, pp. 1658-1662, 1979.

[32] D. T. Denhardt, D. H. Dressler, and A. Hathaway, "The abortive replication of PhiX174 DNA in a recombinationdeficient mutant of Escherichia coli," Proceedings of the National Academy of Sciences of the United States of America, vol. 57, no. 3, pp. 813-820, 1967.

[33] J. Atkinson, M. K. Gupta, C. J. Rudolph, H. Bell, R. G. Lloyd, and P. McGlynn, "Localization of an accessory helicase at the replisome is critical in sustaining efficient genome duplication," Nucleic Acids Research, vol. 39, no. 3, pp. 949957, 2011.

[34] H. Boubakri, A. L. de Septenville, E. Viguera, and B. Michel, "The helicases DinG, Rep and UvrD cooperate to promote replication across transcription units in vivo," The EMBO Journal, vol. 29, no. 1, pp. 145-157, 2010.

[35] M. A. Petit and D. Ehrlich, "Essential bacterial helicases that counteract the toxicity of recombination proteins," $E M B O$ Journal, vol. 21, no. 12, pp. 3137-3147, 2002. 
[36] C. J. Cadman, S. W. Matson, and P. McGlynn, "Unwinding of forked DNA structures by UvrD," Journal of Molecular Biology, vol. 362 , no. 1, pp. 18-25, 2006.

[37] R. Lestini and B. Michel, "UvrD and UvrD252 cunteract RecQ, RecJ, and RecFOR in a rep mutant of Escherichia coli," Journal of Bacteriology, vol. 190, no. 17, pp. 5995-6001, 2008.

[38] X. Veaute, S. Delmas, M. Selva et al., "UvrD helicase, unlike Rep helicase, dismantles RecA nucleoprotein filaments in Escherichia coli," EMBO Journal, vol. 24, no. 1, pp. 180-189, 2005.

[39] I. Mellon and P. C. Hanawalt, "Induction of the Escherichia coli lactose operon selectively increases repair of its transcribed DNA strand," Nature, vol. 342, no. 6245, pp. 95-98, 1989.

[40] D. J. Crowley and P. C. Hanawalt, "The SOS-dependent upregulation of uvrD is not required for efficient nucleotide excision repair of ultraviolet light induced DNA photoproducts in Escherichia coli," Mutation Research, vol. 485, no. 4, pp. 319329, 2001.

[41] D. Yu, H. M. Ellis, E. C. Lee, N. A. Jenkins, N. G. Copeland, and D. L. Court, "An efficient recombination system for chromosome engineering in Escherichia coli," Proceedings of the National Academy of Sciences of the United States of America, vol. 97, no. 11, pp. 5978-5983, 2000.

[42] R. H. Rothman and A. J. Clark, "Defective excision and postreplication repair of UV-damaged DNA in a recL mutant strain of E. coli K-12," Molecular and General Genetics, vol. 155, no. 3, pp. 267-277, 1977.

[43] H. Ogawa, K. Shimada, and J. I. Tomizawa, "Studies on radiation-sensitive mutants of E. coli-I. Mutants defective in the repair synthesis," Molecular \& General Genetics, vol. 101, no. 3, pp. 227-244, 1968.

[44] M. J. Florés, N. Sanchez, and B. Michel, "A fork-clearing role for UvrD," Molecular Microbiology, vol. 57, no. 6, pp. 1664 1675, 2005.

[45] R. Lestini and B. Michel, "UvrD controls the access of recombination proteins to blocked replication forks," $E M B O$ Journal, vol. 26, no. 16, pp. 3804-3814, 2007.

[46] J. R. Donaldson, C. T. Courcelle, and J. Courcelle, "RuvABC is required to resolve holliday junctions that accumulate following replication on damaged templates in Escherichia coli," Journal of Biological Chemistry, vol. 281, no. 39, pp. 28811-28821, 2006.

[47] I. Husain, B. Van Houten, and D. C. Thomas, "Effect of DNA polymerase I and DNA helicase II on the turnover rate of UvrABC excision nuclease," Proceedings of the National Academy of Sciences of the United States of America, vol. 82, no. 20, pp. 6774-6778, 1985.

[48] H. Maki, T. Horiuchi, and A. Kornberg, "The polymerase subunit of DNA polymerase III of Escherichia coli. I. Amplification of the dnaE gene product and polymerase activity of the $\alpha$ subunit," Journal of Biological Chemistry, vol. 260, no. 24, pp. 12982-12986, 1985.

[49] S. Maki and A. Kornberg, "DNA polymerase III holoenzyme of Escherichia coli. III. Distinctive processive polymerases reconstituted from purified subunits," Journal of Biological Chemistry, vol. 263, no. 14, pp. 6561-6569, 1988.

[50] K. H. Chow and J. Courcelle, "RecBCD and RecJ/RecQ initiate DNA degradation on distinct substrates in UV-irradiated Escherichia coli," Radiation Research, vol. 168, no. 4, pp. 499506, 2007.

[51] J. J. Belle, A. Casey, C. T. Courcelle, and J. Courcelle, "Inactivation of the DnaB helicase leads to the collapse and degradation of the replication fork: a comparison to UVinduced arrest," Journal of Bacteriology, vol. 189, no. 15, pp. 5452-5462, 2007.
[52] C. P. Guy, J. Atkinson, M. K. Gupta et al., "Rep provides a second motor at the replisome to promote duplication of protein-bound DNA," Molecular Cell, vol. 36, no. 4, pp. 654666, 2009. 

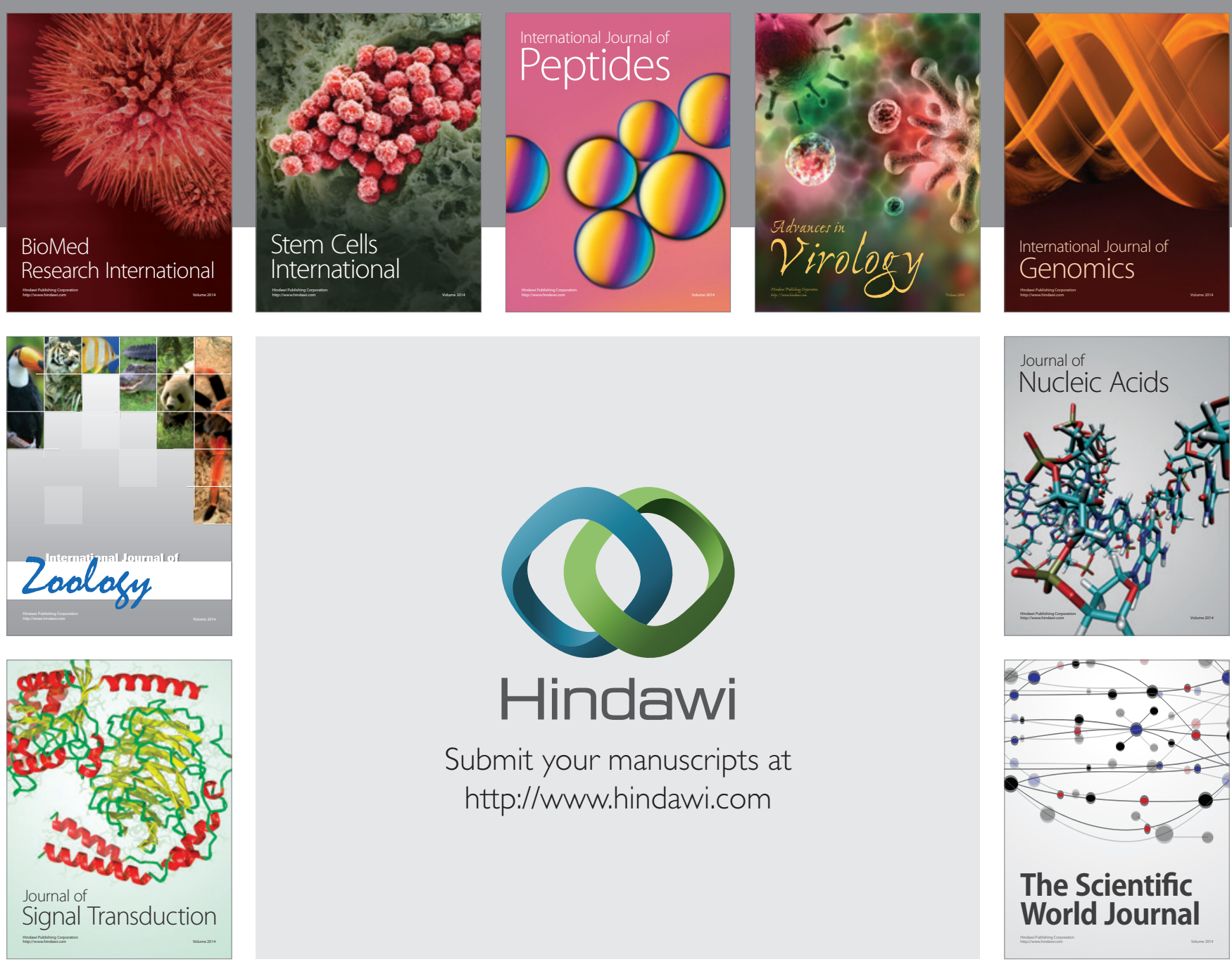

Submit your manuscripts at

http://www.hindawi.com
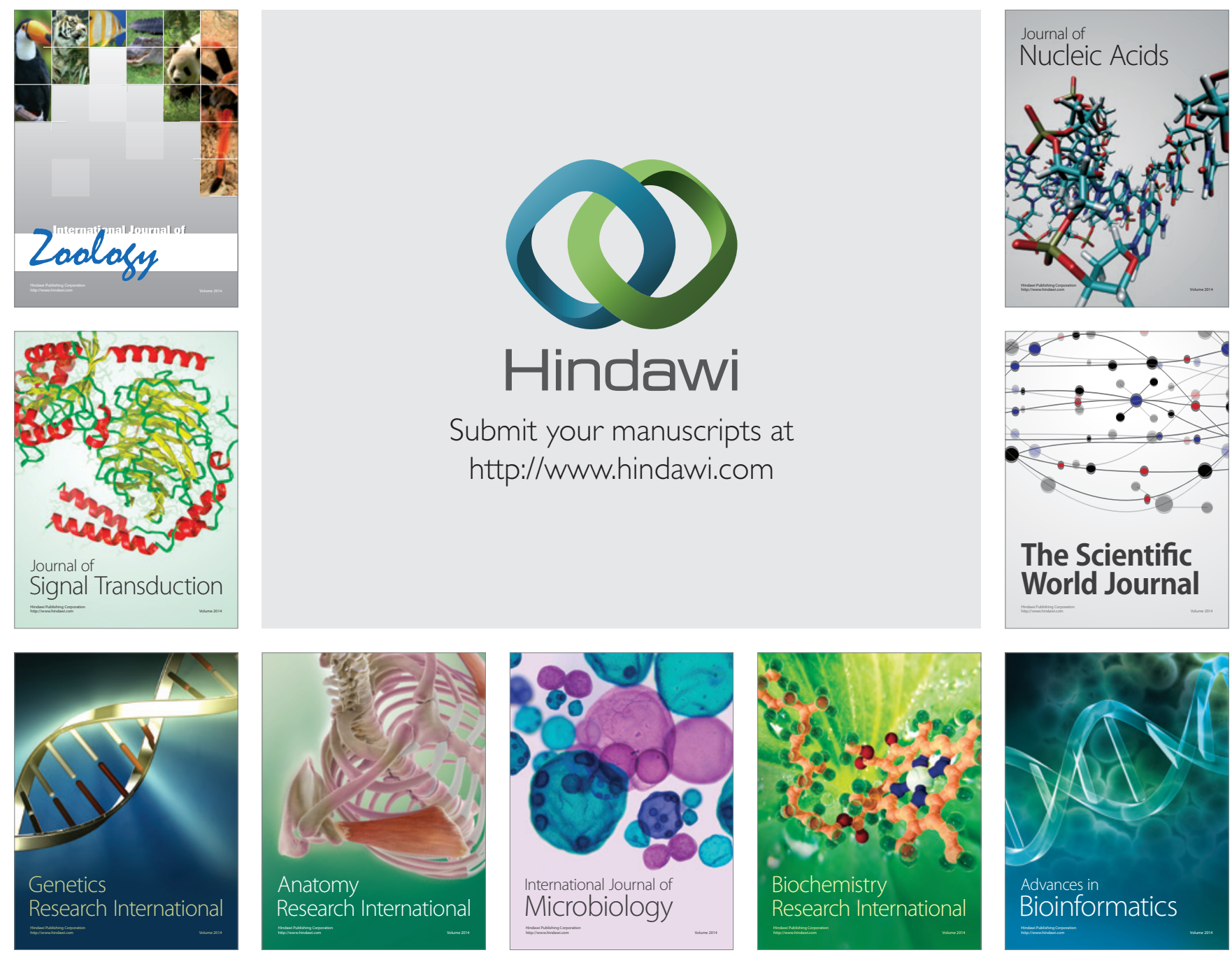

The Scientific World Journal
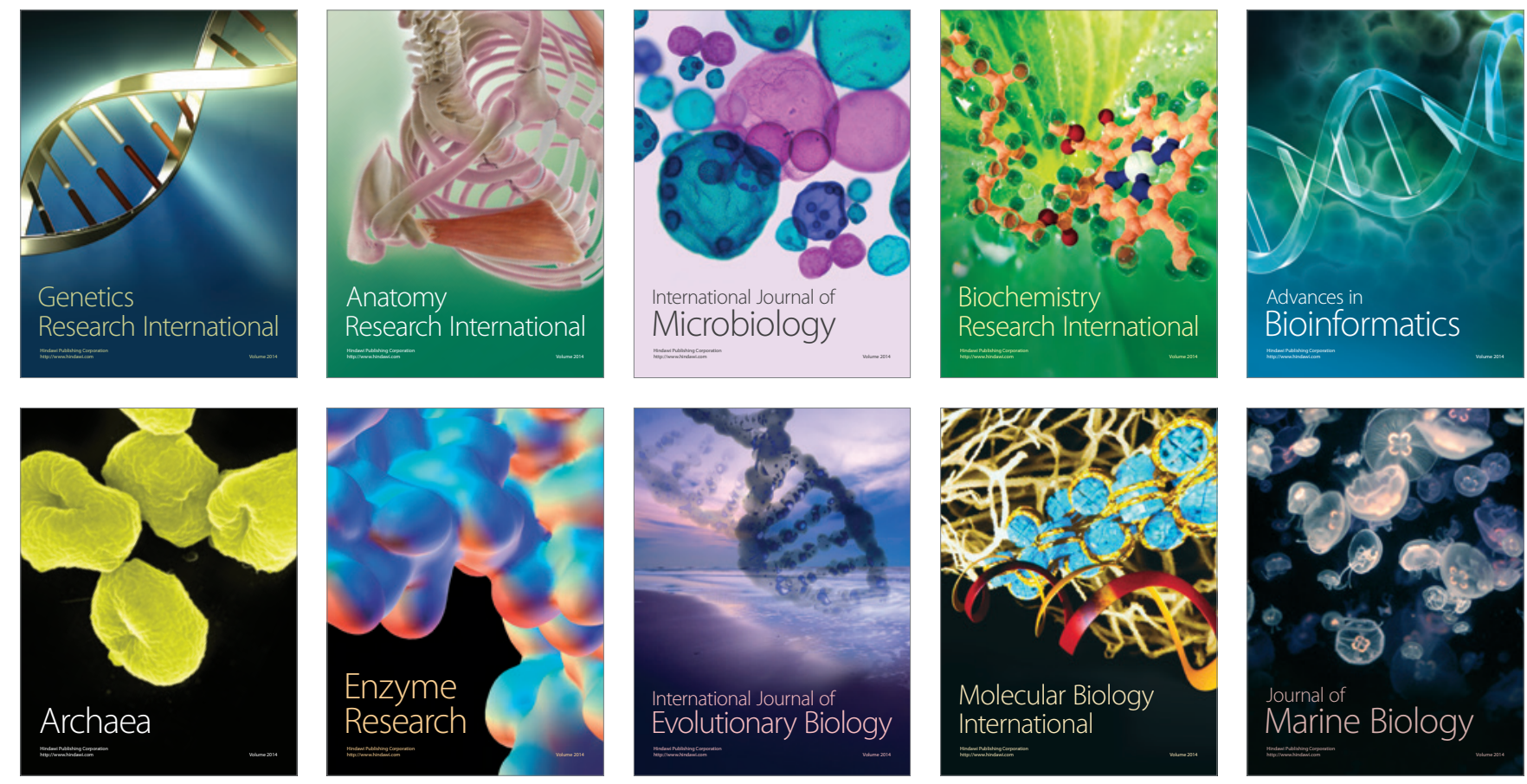